\title{
Experimental study of airway pressure release ventilation in the treatment of acute respiratory distress syndrome
}

\author{
GUAN-JIE HAN, JIA-QIONG LI, CUI-GAI PAN, JING-XI SUN, ZAI-XIANG SHI, JI-YUAN XU and MAO-QIN LI
}

\author{
Department of Intensive Care Unit, Xuzhou Central Hospital, The Affiliated Xuzhou Hospital of \\ Medical College of Southeast University, Xuzhou, Jiangsu 221009, P.R. China
}

Received July 25, 2016; Accepted March 22, 2017

DOI: $10.3892 /$ etm.2017.4718

\begin{abstract}
Airway pressure release ventilation (APRV) is a ventilator mode which has demonstrated potential benefits in acute respiratory distress syndrome (ARDS) patients. We therefore sought to compare relevant pulmonary data and safety outcomes of this mode to the conventional ventilation and sustained inflation. Canines admitted after intravenous injection of oleic acid requiring mechanical ventilation were randomly divided into 3 groups $(n=6)$, namely conventional ventilation group, low tidal volume ventilation with recruitment group (LTV+SI) and APRV group. The changes of oxygenation, ventilation, airway pressure, inflammatory reaction and hemodynamics at the basic state were observed at $0,1,2$ and $4 \mathrm{~h}$ during the experiment. The levels of $\mathrm{PaO}_{2} / \mathrm{FiO}_{2}$ in APRV group were higher than LTV+SI group at 2 and $4 \mathrm{~h}(\mathrm{P}<0.05)$. In APRV group, the $\mathrm{PCO}_{2}$ levels at 1,2 and $4 \mathrm{~h}$ is much lower than LTV+SI group $(\mathrm{P}<0.05)$. Outcome variables showed no differences between APRV, LVT+SI and conventional mechanical ventilation for plateau airway pressure ( $24 \pm 1$ vs. $29 \pm 3$ vs. $25 \pm 4$ ), mean arterial pressure $(92.9 \pm 16.5$ vs. $85.8 \pm 21.4$ vs. $88.7 \pm 24.4)$, cardiac index ( $4.3 \pm 1.7$ vs. $3.5 \pm 1.9$ vs. $3.4 \pm 2.1), \mathrm{ERO}_{2}(13.4 \pm 10.3$ vs. $16.1 \pm 6.8$ vs. $17.6 \pm 9.1)$, lac $(2.5 \pm 1.7$ vs. $3.1 \pm 1.6$ vs. $3.9 \pm 1.9)$, tumor necrosis factor (TNF)- $\alpha(132 \pm 11$ vs. $140 \pm 6$ vs. $195 \pm 13)$ and matrix metalloproteinase (MMP)-9. For canines sustaining acute respiratory distress syndrome requiring mechanical ventilation, APRV can significantly improve oxygenation and keep hemodynamic stability compared with LTV+SI. The results of TNF- $\alpha$ and MMP-9 suggest that APRV could be as protective for ARDS as LTV with recruitment group.
\end{abstract}

Correspondence to: Dr Mao-Qin Li, Department of Intensive Care Unit, Xuzhou Central Hospital, The Affiliated Xuzhou Hospital of Medical College of Southeast University, 199 South Jiefang Road, Xuzhou, Jiangsu 221009, P.R. China

E-mail: 1i_maoqin1@163.com

Key words: airway pressure release ventilation, low tidal volume ventilation, sustained inflation

\section{Introduction}

In 2000, the Acute Respiratory Distress Syndrome (ARDS) Network showed that low tidal volume (LTV) ventilation can significantly reduce ARDS mortality as a major breakthrough for ARDS mechanical ventilation (1). LTV, however, is the necessary measure to prevent the excessive expansion of the alveolar. In order to be able to improve oxygenation significantly, lung recruitment is proposed as adjunct to open up the lung. However, with further studies, researchers have found that RM cannot improve the prognosis of ARDS patients (2).

Airway pressure release ventilation (APRV) is a ventilator mode that is pressure-control, time-triggered, pressure-limited and time-cycled, while it allows spontaneous breathing at any phase of the ventilator cycle. APRV as a mode of mechanical ventilation, by setting high airway pressure, long inspiratory time and short expiratory time to keep alveolar in the open state, so as to improve oxygenation (3).

APRV seemed more protective than the other conventional mechanical ventilations (CMVs) in an experimental model of ARDS, because increases in BALF HMGB1 and pulmonary oedema caused by ALI were significantly attenuated in the APRV group (4). We hypothesized that APRV improve oxygenation without increased complications. Our study aimed to determine the effects of APRV on gas exchange, hemodynamics, and histological signs of lung injury in ARDS.

\section{Materials and methods}

Animal preparation. Experiments described in our study were reviewed and approved by the Animal Research and Use Committee of Xuzhou University School of Medicine. Twenty-four mongrel dogs (weight, $13.3 \pm 1.2 \mathrm{~kg}$ ) were provided by the Experimental Animal Center of Xuzhou Medical College. Animals were anesthetized by injecting sodium pentobarbital $(30 \mathrm{mg} / \mathrm{kg})$ through the forelimb vein. With the animal supine, the trachea was intubated using a tracheal tube (inner diameter, $7.0 \mathrm{~mm}$ ) which was connected to a PB840 ventilator (Taike Equipment Co.). Mechanical ventilation [tidal volume $(\mathrm{Vt}), 10 \mathrm{ml} / \mathrm{kg}$; inspiratory:expiratory $(\mathrm{I} / \mathrm{E})$ ratio, 1:2; respiratory rate, 30 breaths $/ \mathrm{min} ; \mathrm{FiO}_{2}$, 0.4; PEEP, $0 \mathrm{cmH}_{2} \mathrm{O}$ ] was started.

Catheters were placed in the right internal jugular vein and right femoral artery connected to pulse indicator continuous 
cardiac output (PiCCO) instrument (Pulsion Medical Systems SE, Munich, Germany) for continuous monitoring of heart rate (HR), mean arterial pressure (MAP), central venous pressure (CVP) and cardiac index (CI).

Lung injury. Oleic acid $(0.2 \mathrm{ml} / \mathrm{kg})$ mixed with the same amount of autologous blood was infused intravenously within $30 \mathrm{~min}$ until the vital signs were stable for $30 \mathrm{~min}$. Arterial blood gas was performed every $30 \mathrm{~min}$ until $\mathrm{PaO}_{2} / \mathrm{FiO}_{2} \leq 100 \mathrm{mmHg}$ (4) $(1 \mathrm{mmHg}=0.133 \mathrm{kPa})$. Sixty minutes after stabilization of lung injury, ventilation strategies were decided.

During the study, continuous intravenous infusion of sodium pentobarbital 1 to $2 \mathrm{mg} /(\mathrm{kg} \cdot \mathrm{h})$ was maintained to keep the animals in a state of general anesthesia. A slow infusion $6 \mathrm{ml} /(\mathrm{kg} \cdot \mathrm{h})$ was given to maintain MAP above $80 \mathrm{mmHg}$, and CVP more than $5 \mathrm{mmHg}$.

Experimental groups. After establishment of ARDS, the canines were randomly assigned to 4 groups of 6 animals each: i) Normal group; ii) conventional ventilation group (CMV). The animals were ventilated with $\mathrm{Vt} 10 \mathrm{ml} / \mathrm{kg}$, f $35 \mathrm{bpm}, \mathrm{I}: \mathrm{E}$ ratio $1: 2, \mathrm{FiO}_{2} 0.6$ and PEEP $5 \mathrm{cmH}_{2} 0$; iii) LTV combined with sustained inflation (LTV+SI). The animals in this group were ventilated with Vt $6 \mathrm{ml} / \mathrm{kg}, 40 \mathrm{bpm}$, I:E ratio 1:2, $\mathrm{FiO}_{2} 0.6$ and PEEP $5 \mathrm{cmH}_{2} 0$; and SI was given $10 \mathrm{~min}$ before the ARDS 1 , 2 and 4 h time-points. The SI implementation: Ventilation mode was changed to continuous positive airway pressure + pressure support ventilation (CPAP PSV), pressure support level was reduced to $0 \mathrm{cmH}_{2} \mathrm{O}$, and PEEP adjusted to $40 \mathrm{cmH}_{2} \mathrm{O}$ for $30 \mathrm{sec}$; and iv) APRV, the ventilation mode was switched to APRV with the baseline ventilator setting determined by the adult recommended values: Airway pressure (P-high), $24 \mathrm{cmH}_{2} \mathrm{O}$; low pressure (P-low), $5 \mathrm{cmH}_{2} \mathrm{O}$; inspiratory time (T-high), $2.8 \mathrm{sec}$; the time at low pressure (T-low), $0.4 \mathrm{sec}$; and $\mathrm{FiO}_{2}, 0.6 \mathrm{sec}$. Animals in APRV group were allowed to spontaneously breath throughout the study.

Hemodynamic and pulmonary mechanics. Arterial blood gases (ABGs), HR, MAP, CVP, CI were recorded at baseline, after lung injury, and 1,2 and $4 \mathrm{~h}$ after randomization to ventilation strategy. CI was measured using a thermos-dilution technique and recorded as the average of three measurements. Pulmonary parameters such as respiratory rate (RR), plateau pressure (P-plat), Vt, and static compliance (Cst) were measured and calculated in line with the Galileo ventilator before and after injury, of 1, 2 and $4 \mathrm{~h}$ time-points. P-plat was measured at the end of an inspiratory pause of $5 \mathrm{sec}$. Cst was calculated according to formula VT/(P-plat - PEEP).

Histology. Samples were obtained from the lower right lobe as the lung was fixed in formalin for at least $48 \mathrm{~h}$. Then the 4-mm thick sections were embedded in paraffin and stained with hematoxylin and eosin (H\&E). We observed the sections from 5 points: Alveolar congestion, alveolar wall thickness, oedema, neutrophil infiltration and alveolar distension or destruction.

Serum tumor necrosis factor (TNF)- $\alpha$ and interleukin (IL)-10. TNF- $\alpha$ and IL-10 levels in serum were determined by canine-specific enzyme-linked immunosorbent assay (ELISA) kits (Biovalue Co., Ltd., Shanghai, China) using the manufacturer's specified instructions.

Western blot analysis. The tissue extracts were measured by a modified Lowry method. Then the sample was mixed with $4 \mathrm{X}$ sample buffer and boiled for $5 \mathrm{~min}$. Equal amount of protein samples were separated on an $8 \%$ sodium dodecyl sulfate (SDS)-polyacrylamide gel electrophoresis (PAGE), then the proteins were semi-dried and electrophoretically transferred onto a nitrocellulose membrane (NC) and blocked for $2 \mathrm{~h}$ in $3 \%$ bovine serum albumin (BSA) at room temperature. The membranes were incubated with rabbit polyclonal MMP9 antibody (dilution, 1:500; cat. no. ab73734) and rabbit monoclonal TIMP-1 antibody (dilution, 1:500; cat. no. ab211926) (both from Abcam, Cambridge, MA, USA) and then stored overnight at $4{ }^{\circ} \mathrm{C}$. The next day the membranes were incubated with goat anti-rabbit secondary antibody (dilution, 1:2,000; cat. no. ab6721) (Abcam) at room temperature for $2 \mathrm{~h}$. Then the color was developed using NBT/BCI (Promega, Madison, WI, USA). Finally, the signals were quantified with QuantityOne software (Bio-Rad Laboratories, Inc., Hercules, CA, USA).

Statistical analysis. Data values are presented as mean \pm SD. Serum TNF- $\alpha$ and IL-10, W/D weight ratio and other data were performed using repeated-measures analysis of variance (ANOVA). The intra-group comparisons of control data (after injury) and data obtained at 1,2 and $4 \mathrm{~h}$, and the intergroup comparisons at each time interval were analyzed using repeated-measures ANOVA. $\mathrm{P}<0.05$ was considered to indicate a statistically significant difference.

\section{Results}

All the animals developed severe lung injury $\mathrm{PaO}_{2} / \mathrm{FiO}_{2}$ $<100 \mathrm{mmHg}$, and $\mathrm{PaO}_{2} / \mathrm{FiO}_{2}$ values were significantly increased after treatment using APRV and LTV+SI (Table I). While the $\mathrm{PaO}_{2} / \mathrm{FiO}_{2}$ values were lower in the CMV group than in the LTV+SI and APRV group; the $\mathrm{PaO}_{2} / \mathrm{FiO}_{2}$ values were higher in APRV groups than the LTV+SI group. There was no significant difference in APRV group for $\mathrm{PaCO}_{2}$ values. The $\mathrm{PaCO}_{2}$ values were higher in the LTV+SI group than the APRV group. P-plat in APRV group was significantly different with LTV+SI group $(\mathrm{P}<0.05)$ at $4 \mathrm{~h}$ (Table I). Compared with base state, minute volume was lower at 1,2 and $4 \mathrm{~h}$ in LTV+SI group than CMV and APRV group $(\mathrm{P}<0.05)$ (Table I). There were no significant differences in Cst among the groups $(\mathrm{P}>0.05)$ (Table I).

HR in APRV group at $4 \mathrm{~h}$ and in LTV+SI group at $1 \mathrm{~h}$ was significantly different compared with base state $(\mathrm{P}<0.05)$. Compared with CMV group, HR in APRV group at $1 \mathrm{~h}$ was significant lower $(\mathrm{P}<0.05)$ (Table II). MAP in the groups at 1 , 2 and $4 \mathrm{~h}$ was not statistically significant $(\mathrm{P}>0.05)$ (Table II). $\mathrm{CI}$ and CVP in APRV group did not have significant difference compared with CMV and LTV+SI at 1, 2 and $4 \mathrm{~h}(\mathrm{P}>0.05)$. Although CVP in CMV group was higher at 1,2 and $4 \mathrm{~h}$ than $0 \mathrm{~h}$, it was not statistically different $(\mathrm{P}>0.05)$ (Table II).

MMP-9 in CMV group was significantly higher than Con, LTV+SI and APRV group. In APRV group, MMP-9 level was higher than LTV+SI group, but there was no 
Table I. The changes of gas exchange and pulmonary mechanics in ARDS.

\begin{tabular}{|c|c|c|c|c|c|}
\hline Parameters & Baseline & After injury & $1 \mathrm{~h}$ & $2 \mathrm{~h}$ & $4 \mathrm{~h}$ \\
\hline \multicolumn{6}{|l|}{$\mathrm{P} / \mathrm{F}(\mathrm{mmHg})$} \\
\hline CMV & $557 \pm 68$ & $69 \pm 14$ & $89 \pm 26$ & $79 \pm 19$ & $73 \pm 20$ \\
\hline $\mathrm{LTV}+\mathrm{SI}$ & $563 \pm 51$ & $74 \pm 24$ & $199 \pm 35^{a, b}$ & $216 \pm 45^{\mathrm{a}, \mathrm{b}}$ & $239 \pm 50^{\mathrm{a}, \mathrm{b}}$ \\
\hline APRV & $581 \pm 56$ & $74 \pm 23$ & $222 \pm 41^{\mathrm{a}, \mathrm{b}}$ & $322 \pm 53^{\mathrm{a}-\mathrm{c}}$ & $346 \pm 62^{a-c}$ \\
\hline \multicolumn{6}{|c|}{$\mathrm{PaCO}_{2}(\mathrm{mmHg})$} \\
\hline CMV & $35 \pm 5$ & $46 \pm 6$ & $46 \pm 5$ & $47 \pm 7^{c}$ & $47 \pm 6$ \\
\hline $\mathrm{LTV}+\mathrm{SI}$ & $35 \pm 6$ & $45 \pm 5$ & $52 \pm 6$ & $53 \pm 5^{\mathrm{a}}$ & $57 \pm 7^{\mathrm{a}, \mathrm{b}}$ \\
\hline APRV & $34 \pm 5$ & $43 \pm 8$ & $40 \pm 6^{c}$ & $39 \pm 6^{c}$ & $39 \pm 6^{c}$ \\
\hline \multicolumn{6}{|c|}{ P-plat $\left(\mathrm{cmH}_{2} \mathrm{O}\right)$} \\
\hline CMV & $11 \pm 2$ & $20 \pm 3$ & $25 \pm 2$ & $24 \pm 3$ & $25 \pm 4$ \\
\hline LTV+SI & $12 \pm 1$ & $18 \pm 5$ & $26 \pm 4$ & $26 \pm 2$ & $29 \pm 3$ \\
\hline APRV & $11 \pm 2$ & $21 \pm 3$ & $24 \pm 1$ & $23 \pm 2$ & $24 \pm 1^{c}$ \\
\hline \multicolumn{6}{|c|}{$\mathrm{MV}(\mathrm{ml} / \mathrm{min})$} \\
\hline CMV & $3,956 \pm 235$ & $4,150 \pm 187$ & $4,132 \pm 175$ & $4,168 \pm 175$ & $4,216 \pm 229$ \\
\hline $\mathrm{LTV}+\mathrm{SI}$ & $3,833 \pm 314$ & $4,078 \pm 281$ & $3,083 \pm 471^{\mathrm{a}, \mathrm{b}}$ & $3,167 \pm 408^{a, b}$ & $3,209 \pm 442^{a, b}$ \\
\hline APRV & $4,024 \pm 210$ & $4,135 \pm 261$ & $4,334 \pm 427^{\mathrm{c}}$ & $4,371 \pm 487^{c}$ & $4,438 \pm 476^{c}$ \\
\hline \multicolumn{6}{|c|}{$\mathrm{Cst}\left(\mathrm{ml} / \mathrm{cmH}_{2} \mathrm{O}\right)$} \\
\hline CMV & $25 \pm 9$ & $10 \pm 5$ & $7 \pm 3$ & $6 \pm 2$ & $5 \pm 3$ \\
\hline $\mathrm{LTV}+\mathrm{SI}$ & $24 \pm 10$ & $8 \pm 6$ & $5 \pm 2$ & $5 \pm 1$ & $4 \pm 2$ \\
\hline APRV & $26 \pm 8$ & $8 \pm 7$ & $7 \pm 3$ & $8 \pm 2$ & $7 \pm 3$ \\
\hline
\end{tabular}

ARDS, acute respiratory distress syndrome; P/F, oxygenation index; CMV, conventional mechanical ventilation; LTV+SI, low tidal volume ventilation combined with sustained inflation; PIP, peak inspiratory pressure; P-plat, plateau pressure; MV, minute volume; Cdyn, dynamic compliance. ${ }^{\mathrm{a}} \mathrm{P}<0.05$ vs. after injury; ${ }^{\mathrm{b}} \mathrm{P}<0.05$ vs. $\mathrm{CMV}$; ${ }^{\mathrm{P}} \mathrm{P}<0.05$ vs. LTV+SI.

significant difference $(\mathrm{P}>0.05)$ (Fig. 1A). There was no obvious TIMP-1 in CMV group. But it was much higher in Con, LTV+SI and APRV group than CMV group $(\mathrm{P}<0.05)$. The difference between the three groups was not statistically significant $(\mathrm{P}>0.05)$ (Fig. $1 \mathrm{~B})$. Only in CMV group, MMP-9/TIMP-1 $>1$, and the difference compared with Con, LTV+SI and APRV group was significant $(\mathrm{P}<0.05)$.

The Con group showed alveolar structural integrity, the alveolar wall without edema and the normal structure of lung microvascular (Fig. 2A). In CMV group, the alveolar septum widened with more bleeding, and a few inflammatory cells (Fig. 2B). In LTV+SI group, it can be seen that alveolar septum was slightly widened, but bleeding was heavier and inflammatory cell infiltration was obvious. Alveolar septa fractured occasionally (Fig. 2C). Alveolar septa of APRV group slightly widened. Alveolar collapse was slightly lighter than the CMV group and LTV+SI group, and with less inflammatory cell infiltration. Alveolar septa fracture was occasionally seen (Fig. 2D).

Concentration of TNF- $\alpha$ in CMV, LTV+SI and APRV group was more than the normal group $(\mathrm{P}<0.05)$. In $\mathrm{CMV}$ group, it was much lower than LTV+SI and APRV group, the difference was statistically significant $(\mathrm{P}<0.05)$. The difference between LTV+SI and APRV group was not significant $(\mathrm{P}>0.05)$. The levels of IL-10 in LTV+SI and APRV group were significantly lower than $\mathrm{CMV}$, the changes were statistically significant $(\mathrm{P}<0.05)$. However, in APRV group, IL-10 levels are much higher than LTV+SI group $(\mathrm{P}<0.05)$.
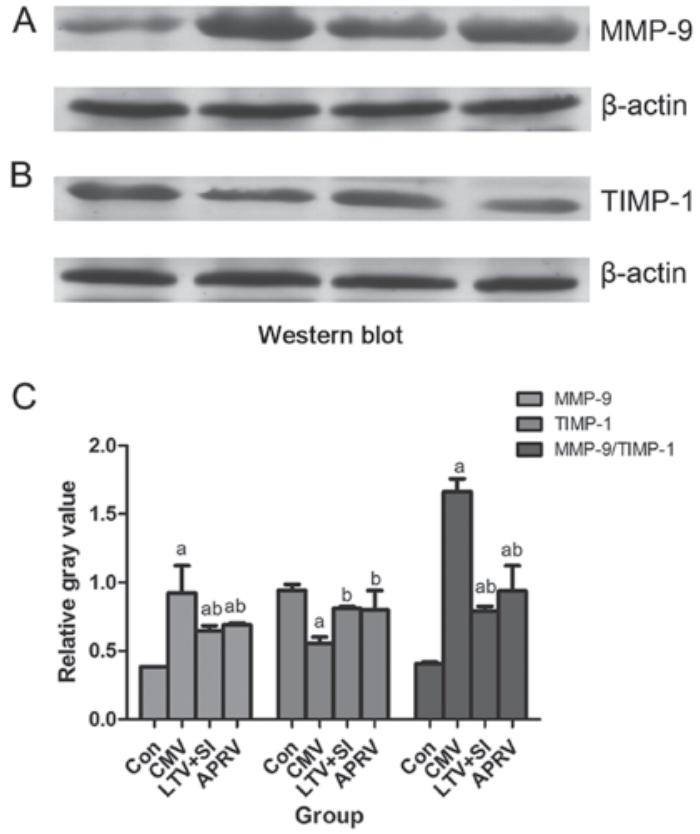

Figure 1. (A) MMP-9; (B) TIMP-1 in lung tissue. The groups represent canines treated as follows: Normal, CMV, LTV+SI and APRV; (C) MMP-9 level in APRV group was higher than LTV+SI group, but there was no significant difference $(\mathrm{P}>0.05)$. In CMV group, MMP-9/TIMP-1 $>1$, and the difference compared with other groups was significant $(\mathrm{P}<0.05)$. MMP-9, matrix metalloproteinase-9; TIMP-1, tissue inhibitor of metalloproteinase-1; CMV, conventional mechanical ventilation; LTV+SI, low tidal volume ventilation combined with sustained inflation; APRV, airway pressure release ventilation. 
Table II. The changes of hemodynamics in ARDS canines.

\begin{tabular}{|c|c|c|c|c|c|}
\hline Parameters & Baseline & After injury & $1 \mathrm{~h}$ & $2 \mathrm{~h}$ & $4 \mathrm{~h}$ \\
\hline \multicolumn{6}{|l|}{ HR (bpm) } \\
\hline CMV & $135.3 \pm 16.2$ & $143.6 \pm 28.9$ & $139.5 \pm 32.8$ & $145.4 \pm 29.8$ & $152.7 \pm 32.6$ \\
\hline $\mathrm{LTV}+\mathrm{SI}$ & $120.8 \pm 21.4$ & $145.4 \pm 22.7$ & $153.0 \pm 30.2$ & $142.0 \pm 26.7$ & $143.7 \pm 25.1$ \\
\hline APRV & $142.6 \pm 13.4$ & $146.7 \pm 16.9$ & $142.8 \pm 21.1$ & $138.7 \pm 23.2$ & $141.4 \pm 26.3$ \\
\hline \multicolumn{6}{|c|}{ MAP (mmHg) } \\
\hline CMV & $98.3 \pm 11.2$ & $93.0 \pm 17.6$ & $87.4 \pm 18.5$ & $80.1 \pm 19.6$ & $79.7 \pm 24.4$ \\
\hline $\mathrm{LTV}+\mathrm{SI}$ & $100.7 \pm 10.3$ & $95.6 \pm 14.8$ & $89.4 \pm 21.1$ & $82.5 \pm 17.3$ & $79.8 \pm 21.4$ \\
\hline APRV & $104.4 \pm 14.0$ & $92.4 \pm 15.2$ & $90.8 \pm 12.9$ & $89.3 \pm 20.2$ & $85.9 \pm 16.5$ \\
\hline \multicolumn{6}{|c|}{$\mathrm{CI}\left(1 / \mathrm{min} / \mathrm{m}^{2}\right)$} \\
\hline CMV & $4.3 \pm 1.2$ & $4.4 \pm 1.5$ & $3.9 \pm 1.6$ & $3.9 \pm 1.7$ & $3.4 \pm 2.1$ \\
\hline $\mathrm{LTV}+\mathrm{SI}$ & $3.9 \pm 1.5$ & $4.6 \pm 1.7$ & $3.9 \pm 1.9$ & $3.7 \pm 1.8$ & $3.5 \pm 1.9$ \\
\hline APRV & $4.2 \pm 1.1$ & $4.7 \pm 1.4$ & $4.3 \pm 2.0$ & $4.4 \pm 1.6$ & $4.3 \pm 1.7$ \\
\hline \multicolumn{6}{|c|}{$\begin{array}{l}\text { SVRI } \\
\left(\mathrm{dyn} \cdot \mathrm{sec} / \mathrm{cm}^{2} / \mathrm{m}^{2}\right)\end{array}$} \\
\hline CMV & $1,453.4 \pm 203.5$ & $1,508.1 \pm 229.7$ & $1,613.2 \pm 241.2$ & $1,752.1 \pm 301.7^{\mathrm{a}}$ & $1,748.9 \pm 298.4^{a}$ \\
\hline $\mathrm{LTV}+\mathrm{SI}$ & $1,398.2 \pm 162.6$ & $1,433.8 \pm 167.3$ & $1,502.6 \pm 157.4$ & $1,489.0 \pm 173.4^{\mathrm{b}}$ & $1,483.8 \pm 189.3^{b}$ \\
\hline APRV & $1,438.3 \pm 234.9$ & $1,472.4 \pm 216.6$ & $1,441.3 \pm 183.4$ & $1,456.3 \pm 190.8^{b}$ & $1,463.5 \pm 188.2^{b}$ \\
\hline \multicolumn{6}{|c|}{ CVP (mmHg) } \\
\hline CMV & $8.2 \pm 2.1$ & $9.3 \pm 3.4$ & $12.2 \pm 3.2$ & $13.4 \pm 4.3$ & $13.6 \pm 3.9$ \\
\hline $\mathrm{LTV}+\mathrm{SI}$ & $7.8 \pm 1.9$ & $10.1 \pm 2.3$ & $11.6 \pm 2.7$ & $12.1 \pm 2.4$ & $11.3 \pm 2.9$ \\
\hline APRV & $8.6 \pm 1.6$ & $9.6 \pm 1.8$ & $10.4 \pm 2.1$ & $10.6 \pm 1.7^{\mathrm{c}}$ & $11.2 \pm 2.3$ \\
\hline
\end{tabular}

Values shown are means \pm SD. HR, heart rate; CMV, conventional mechanical ventilation; LTV+SI, low tidal volume ventilation combined with sustained inflation; APRV, airway pressure release ventilation; MAP, mean artery pressure; CI, cardic index; SVRI, systerm vascular resistance index; CVP, central venous pressure. ${ }^{\mathrm{a}} \mathrm{P}<0.05$ vs. after injury; ${ }^{\mathrm{b}} \mathrm{P}<0.05$ vs. $\mathrm{CMV}$; ${ }^{\mathrm{P}}<0.05$ vs. LTV+SI.
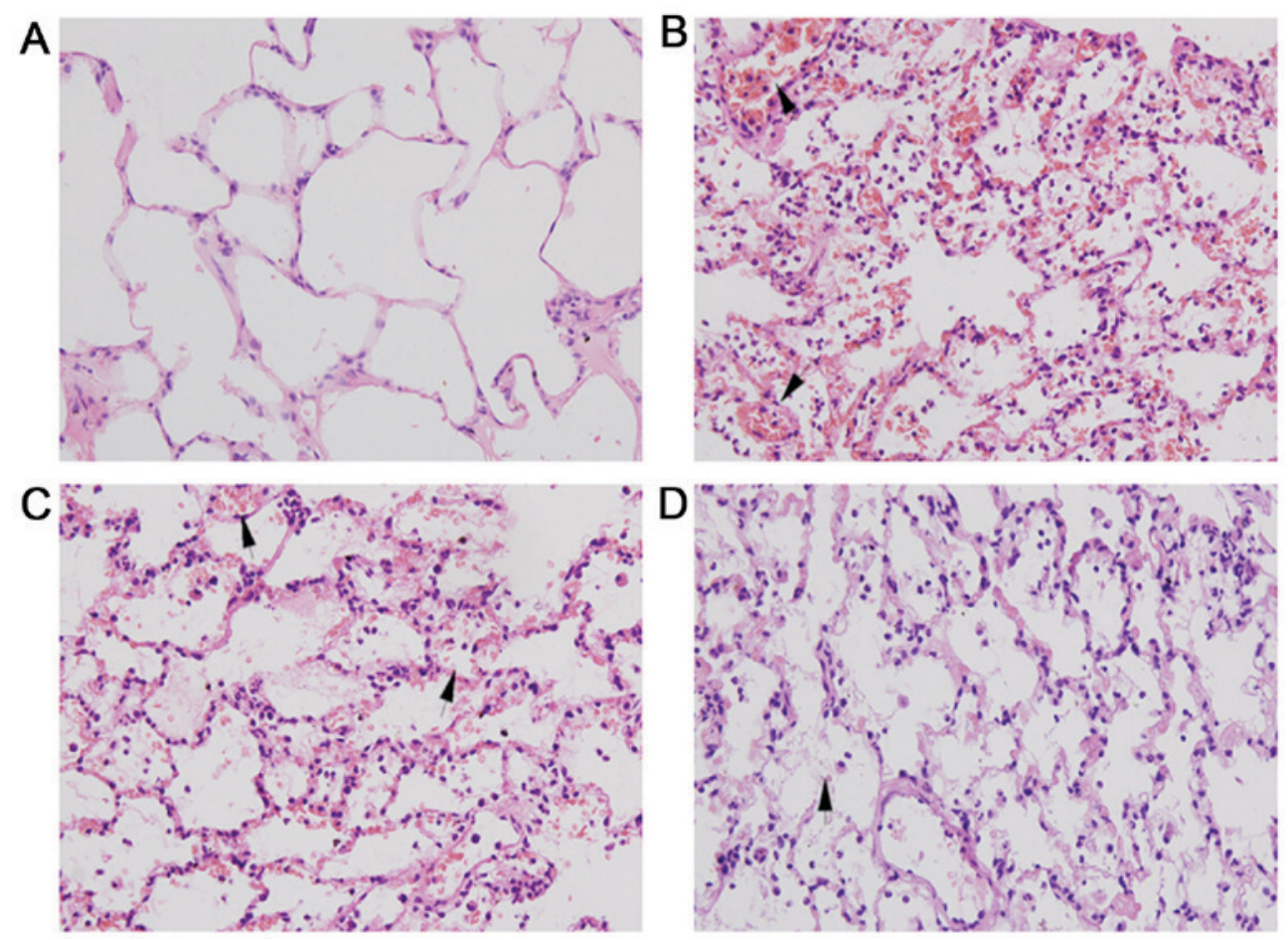

Figure 2. Representative histologic features of lung tissue in each group (H\&E staining; magnification, x200). (A) Normal group; (B) CMV group, significantly greater airspace hemorrhage and vessel congestion (arrow); (C) LTV+SI, moderate vessel congestion (arrow) and leukocyte infiltration; and (D) APRV, greater alveolar fibrin deposition (arrow) and lowest leukocyte infiltration. CMV, conventional mechanical ventilation; LTV+SI, low tidal volume ventilation combined with sustained inflation; APRV, airway pressure release ventilation. 


\section{Discussion}

APRV is mechanical ventilation with pressure-control, timetriggered, pressure-limited and time-cycled, while it allows patients spontaneous breathing throughout the respiratory cycle. Our study suggests APRV may significantly improve oxygenation, keep hemodynamic stability and lower leukocyte infiltration in acute respiratory distress syndrome, based on studies in our canine model of lung injury.

With the progress of treatment, $\mathrm{PaO}_{2} / \mathrm{FiO}_{2}$ in APRV group was significantly higher than the others, without the pulmonary static compliance decreasing and $\mathrm{PCO}_{2}$ increasing. Decreased lung compliance in ARDS can be severe and elevated airway pressures may be necessary to prevent hypoxia $(5,6)$. By setting high airway pressure, long inspiratory time and short expiratory time to keep and maintain alveolar recruitment, so as to improve oxygenation (7). In addition, APRV allows spontaneous breathing to occur independently, which can recruit the dependent lung areas (8). A lung stress and strain concept on VILI has been advocated (9). Stress is defined as the internal distribution of the counterforce per unit of area that balances and reacts to an external load and was represented by transpulmonary pressure. The associated deformation of the structure is called 'strain', which was represented by the ratio of volume change to the resting lung volume. APRV may reduce both stress and strain because APRV uses longer inflation duration in recruited lung rather than a larger Vt. In this study, we determined the P-high levels of the APRV group to receive lung recruitment. From the histopathology results, over distension was not definitely significant in the APRV group compared with other groups. The alveolar stresses associated with a long inflation time and the rapid flow reversals associated with the deflation-reinflation APRV pattern may have an injurious effect (9).

In CMV and LTV+SI group, HR and MAP decreased significantly, while CI showed a downward trend. In APRV group, HR did not have significant changes and MAP remained stable. APRV can sustain the ARDS canine hemodynamics stable. In APRV group, the diaphragm can significantly reduce the decline in intrathoracic pressure in spontaneous breathing, so that the transpulmonary pressure and right atrial pressure also decreased with venous return increasing, ultimately leading increase in cardiac output $(10,11)$.

The results suggest that the alveolar wall thicken and edema was not damaged, with little congestion and alveolar collapse in Con group. CMV group widened alveolar septal edema, bleeding was heavier and alveolar hemorrhage was associated with a large number of inflammatory cell infiltration. LTV+SI group, slightly widened the alveolar septa, with severe alveolar hemorrhage, and inflammatory cells; APRV group slightly widened alveolar septa, alveolar collapse was lighter, with occasional alveolar septal rupture. In conclusion, APRV mitigating ARDS alveolar damage is more obvious compared with CMV and LTV+SI group, which may be relevant to the spontaneous breathing. The displacement of the diaphragm during spontaneous breathing is the largest gravity dependent area, which more facilitates the gravity-dependent alveolars rich blood to develop recruitment $(12,13)$. Increased mean airway pressure, particularly by increasing time spent at $\mathrm{pH}$, can recruit collapsed alveolus without increasing peak pressure. Recruiting and holding collapsed lung units open at lower airway pressures reduces low volume lung injury caused by repeated opening and closing of the diseased alveolus (14). In addition, lower airway pressure also prevents excessive stretch of relatively normal lung units (15).

The results suggest that APRV compared with Con can significantly improve ARDS inflammatory reaction, but the degree of improvement may not be different with LTV+SI. Spontaneous breathing with APRV may be too strong (16). As we set P-high at a fixed value rather than changed according to Vt or P-plat. In condition, poor lung compliance, mean alveolar and transmural pressure may significantly increase the above mean airway pressure during spontaneous breathing potentially leading to barotrauma. Which one facilitates a greater understanding of the mechanics of APRV should be considered in a future study (17).

In conclusion, the present study demonstrates that APRV can significantly improve oxygenation and keep hemodynamic stability compared with LTV+SI in ARDS dogs. In addition, whether APRV improves the mortality and other secondary clinical outcomes warrants further investigation.

\section{References}

1. The Acute Respiratory Distress Syndrome Network: Ventilation with lower tidal volumes as compared with traditional tidal volumes for acute lung injury and the acute respiratory distress syndrome. N Engl J Med 342: 1301-1308, 2000.

2. Meade MO, Cook DJ, Guyatt GH, Slutsky AS, Arabi YM, Cooper DJ, Davies AR, Hand LE, Zhou Q, Thabane L, et al; Lung Open Ventilation Study Investigators: Ventilation strategy using low tidal volumes, recruitment maneuvers, and high positive end-expiratory pressure for acute lung injury and acute respiratory distress syndrome: a randomized controlled trial. JAMA 299: 637-645, 2008

3. Modrykamien A, Chatburn RL and Ashton RW: Airway pressure release ventilation: an alternative mode of mechanical ventilation in acute respiratory distress syndrome. Cleve Clin J Med 78: 101-110, 2011.

4. Matsuzawa Y, Nakazawa K, Yamamura A, Akashi T, Kitagaki K, Eishi Y and Makita K: Airway pressure release ventilation reduces the increase in bronchoalveolar lavage fluid high-mobility group box-1 levels and lung water in experimental acute respiratory distress syndrome induced by lung lavage. Eur J Anaesthesiol 27: 726-733, 2010.

5. Habashi NM: Other approaches to open-lung ventilation: airway pressure release ventilation. Crit Care Med 33: S228-S240, 2005.

6. van Kaam AH, Haitsma JJ, De Jaegere A, van Aalderen WM, Kok JH and Lachmann B: Open lung ventilation improves gas exchange and attenuates secondary lung injury in a piglet model of meconium aspiration. Crit Care Med 32: 443-449, 2004.

7. Dries DJ and Marini JJ: Airway pressure release ventilation. J Burn Care Res 30: 929-936, 2009.

8. Putensen C, Zech S, Wrigge H, Zinserling J, Stüber F, Von Spiegel T and Mutz N: Long-term effects of spontaneous breathing during ventilatory support in patients with acute lung injury. Am J Respir Crit Care Med 164: 43-49, 2001.

9. Protti A, Cressoni M, Santini A, Langer T, Mietto C, Febres D, Chierichetti M, Coppola S, Conte G, Gatti S, et al: Lung stress and strain during mechanical ventilation: any safe threshold? Am J Respir Crit Care Med 183: 1354-1362, 2011.

10. Kreyer S, Putensen C, Berg A, Soehle M, Muders T, Wrigge H, Zinserling $\mathrm{J}$ and Hering R: Effects of spontaneous breathing during airway pressure release ventilation on cerebral and spinal cord perfusion in experimental acute lung injury. J Neurosurg Anesthesiol 22: 323-329, 2010.

11. Kaplan LJ, Bailey H and Formosa V: Airway pressure release ventilation increases cardiac performance in patients with acute lung injury/adult respiratory distress syndrome. Crit Care 5: 221-226, 2001 
12. Nakagawa R, Koizumi T, Ono K, Tsushima K, Yoshikawa S, Kubo K and Otagiri T: Cardiovascular responses to high-frequency oscillatory ventilation during acute lung injury in sheep. $\mathbf{J}$ Anesth 21: 340-347, 2007.

13. Kleinman BS, Frey K, VanDrunen M, Sheikh T, DiPinto D, Mason R and Smith T: Motion of the diaphragm in patients with chronic obstructive pulmonary disease while spontaneously breathing versus during positive pressure breathing after anesthesia and neuromuscular blockade. Anesthesiology 97: 298-305, 2002

14. Maxwell RA, Green JM, Waldrop J, Dart BW, Smith PW, Brooks D, Lewis PL and Barker DE: A randomized prospective trial of airway pressure release ventilation and low tidal volume ventilation in adult trauma patients with acute respiratory failure. J Trauma 69: 501-510, 2010.
15. Schreiter D, Reske A, Stichert B, Seiwerts M, Bohm SH, Kloeppel R and Josten C: Alveolar recruitment in combination with sufficient positive end-expiratory pressure increases oxygenation and lung aeration in patients with severe chest trauma. Crit Care Med 32: 968-975, 2004.

16. Porhomayon J, El-Solh AA and Nader ND: Applications of airway pressure release ventilation. Lung 188: 87-96, 2010.

17. Marini JJ and Ravenscraft SA: Mean airway pressure: physiologic determinants and clinical importance - part 1: physiologic determinants and measurements. Crit Care Med 20: 1461-1472, 1992. 